\title{
Predictors of survival of natural killer/T-cell lymphoma, nasal type, in a non-Asian population: a single cancer centre experience
}

\author{
Jule Vásquez, Mariana Serrano, Lourdes Lopez, Cristian Pacheco and Shirley Quintana \\ Department of Medical Oncology, Instituto Nacional de Enfermedades Neoplásicas, de Enfermedades Neoplásicas, Lima 34, Perú
}

Correspondence to: Jule Vásquez. Email: jvasquez@inen.sld.pe

\section{Abstract}

Background: Natural killer/T-cell lymphoma (NKTCL), part of T-cell and NK-cell neoplasms in the World Health Organisation (WHO) classification, is an aggressive lymphoma with poor prognosis more predominantly seen in Asian and South American countries. This study evaluates the factors associated with survival among patients with newly diagnosed NKTCL in Peru.

Methods: Information was abstracted from medical records (MR) for all NKTCL patients >13 years of age at the Instituto Nacional de Enfermedades Neoplasicas (INEN) between 2002 and 2011. The estimate of the survival curves was performed by the Kaplan-Meier method, and the difference was computed by the log-rank test.

Results: Around 226 MR were reviewed, 153 met the selection criteria, the median age was 40 years (14-84). The median progression-free survival (PFS) was 20 months, five year PFS was $42.6 \%$, univariable analysis (UA) showed statistical significance ( $p<0.05$ ) for male sex, non-nasal primary site, advanced clinical stages, B symptoms, poor performance status, regional nodal involvement (RNI). In the multivariate analysis the only poor prognostic factors was primary non-nasal $($ Hazard ratio $(\mathrm{HR})=2.40,95 \%$ confidence interval $(\mathrm{Cl})=1.43-4.02$, $\mathrm{P}=0.01$ ). The median overall survival (OS) was 49 months, five year OS was $48.9 \%$, UA showed statistical significance for non-nasal primary site, advanced clinical stages, B symptoms, lactate dehydrogenase (LDH) > normal, RNI and local tumour invasion. In the multivariate analysis, primary non-nasal was the only poor prognostic factor with $\mathrm{HR}=2.57,95 \% \mathrm{Cl}=1.37-4.83, \mathrm{P}=0.03$.

Conclusions: In Peru, OS of NKTCL is similar to other countries. This result suggests that non-nasal NKTCL is the only poor prognostic factor of OS and PFS.

Keywords: survival, predictors, natural killer/T-cell lymphoma, chemotherapy

Published: 02/11/2016

Received: $26 / 06 / 2016$

ecancer 2016, 10:688 DOI: 10.3332/ecancer.2016.688

Copyright: (c) the authors; licensee ecancermedicalscience. This is an Open Access article distributed under the terms of the Creative Commons Attribution License (http://creativecommons.org/licenses/by/3.0), which permits unrestricted use, distribution, and reproduction in any medium, provided the original work is properly cited. 


\section{Introduction}

Natural killer/T-cell lymphoma (NKTCL) is a rare haematological malignancy which is typically extranodal, and it has two main subtypes: nasal and nasal-type. It is characterised by prominent necrosis and cytotoxic phenotype associated with the Epstein-Barr virus [1]. NKTCL is more prevalent in Asia, Central, and South America [2-9]. The upper aerodigestive tract (nasal cavity, nasopharynx, paranasal sinuses, palate) is commonly involved, with the nasal cavity as the prototype. Extranodal sites of involvement include the skin, soft tissue, and testicles [3, 10-14]. Some cases may also be accompanied by secondary nodal involvement [15].

The survival of NKTCL is poor [13]. Adverse prognostic factors associated with worse survival have been described, such as non-nasal primary, clinical staging, nodal involvement, Ki-67 expression, the International Prognostic Index (IPI), the Korean Prognostic Index (KPI), large cells, local tumour invasiness, and circulating EBV-DNA levels among others [16-25]. However, in our country (Peru), there are no studies assessing prognosis factors in these patients.

The aim of this retrospective study is to describe predictors of OS and PFS as well as clinical and pathological features of patients with NKTCL treated at our centre.

\section{Methods}

\section{Patients}

The study population included all newly diagnosed patients $>13$ years of age with a pathological confirmation of NKTCL seen at the National Institute of Neoplastic Diseases (INEN) in Lima,Peru between January 2002 and December 2011. Patients with other previous cancers, positive serology for HIV, and diagnosis of aggressive NK cell leukaemia, or incomplete MRs were excluded. The diagnosis of NKTCL was based on the WHO 2008 classification of haematopoietic and lymphoid tissues [1]. All cases were reviewed by an expert panel in lymphomas to confirm diagnosis.

\section{Laboratory findings and staging}

Haematological tests, including complete blood count, liver, and renal function tests, and LDH were performed. Local tumour invasion was defined differently according to the two subtypes. The nasal NKTL was defined in accordance with 7th ed., 2010 TNM classification of the American Joint Committee of Cancer. Any nasal NKTCL with T3 or greater were considered as local invasive in the analysis. For non-nasal NKTCL, the definition of local invasiveness differed according to primary sites. For gastrointestinal NKTCL, local invasiveness referred to T4 lesion in TNM system. In NKTCL primarily involving soft tissue such as muscle or skin, invasion of neurovascular structure or bone invasion was considered as local invasion. Regional nodal involvement was defined as the invasion of lymph nodes corresponding to N1, N2, or N3 of the primary lesion based upon TNM staging system. Accordingly, M1 nodes at TNM system were not categorised as regional lymph nodes in the analysis [16].

The staging was based on modified System Cotswolds Ann Arbor [26]. Performance status was evaluated according to the Eastern Cooperative Oncology Group (ECOG) scale [27]. The response was evaluated based on the revised response criteria for lymphomas [28].

\section{Statistical analysis}

A descriptive analysis of the information through frequencies, percentages, and measures of central tendency were performed. OS was defined as the time from the date of diagnosis to date of last visit or death from any cause, and PFS from the initiation of treatment to disease relapse/progression, last follow-up or death from any cause, whichever occurred first. The overall and PFS were estimated with 
the Kaplan-Meier method and differences were tested using the log-rank test. The Cox proportional hazard models were used to identify predictors of survival of NK/T-cell lymphomas. A level of $p<0.05$ was considered for a statistical significance. The multivariate analysis was performed with all factors with statistical significance in the univariate analysis. SPSS version 22.0 was used for statistical analysis.

\section{Results}

\section{Patient characteristics}

A total of 226 patients were seen at our centre during the study period, according to the database of the Department of Epidemiology, 212 records were retrieved, 37 did not receive chemotherapy, 15 had previous treatment, 5 were younger than 13 years, and 2 had metacronic neoplasms. Finally 153 cases were reviewed for analysis. This study was approved by the Institutional Review Board at our institution. The clinical characteristics of the 153 patients are outlined in Table 1. The majority of the patients were primary nasal $(126,82.4 \%)$. The non-nasal primary $(27,17.4 \%)$ included primary lesions at the following sites: Waldeyer's ring $(n=5)$, skin $(n=5)$, oropharynx $(n=3)$, hard palate $(n=3)$, soft tissue $(n=3)$, splenic $(n=1)$, tongue $(n=1)$, gastrointestinal tract $(n=1)$, alveolar ridge $(n=1)$, cervical lymph node $(n=1)$, inguinal lymph node $(n=1)$, larynx $(n=1)$, and hypopharynx (1).

Table 1. Clinical and pathological characteristics.

\begin{tabular}{|l|l|l|}
\hline \multicolumn{1}{|c|}{ Characteristics } & \multicolumn{1}{|c|}{ N } & \multicolumn{1}{c|}{$\%$} \\
\hline Age, years, Median/range & $40 /[14-84]$ & \\
\hline $\begin{array}{l}\text { Age intervals } \\
\leq 60 \text { years old/>60 years old }\end{array}$ & $131 / 22$ & $85.6 / 14.4$ \\
\hline Sex (male/female) & $98 / 55$ & $64.1 / 35.9$ \\
\hline $\begin{array}{l}\text { Primary site } \\
\text { Nasal/Non-nasal }\end{array}$ & $126 / 27$ & $82.4 / 17.4$ \\
\hline $\begin{array}{l}\text { Stage } \\
\text { Early (I, II) } \\
\text { Advanced (III, IV) }\end{array}$ & $134(91 / 43)$ & $\begin{array}{l}87.6 \\
(59.5 / 28.1) \\
19(2 / 17)\end{array}$ \\
\hline $\begin{array}{l}\text { B Symptoms } \\
\text { Yes/No }\end{array}$ & $55 / 98$ & $35.9 / 64.1$ \\
\hline $\begin{array}{l}\text { LDH } \\
>\text { Normal/<Normal/No available }\end{array}$ & $58 / 83 / 12$ & $37.9 / 54.2 / 7.8$ \\
\hline $\begin{array}{l}\text { Performance Status (ECOG) } \\
(1,2,3,4)\end{array}$ & $138 / 15 / 0 / 0$ & $90.2 / 9.8 / 0 / 0$ \\
\hline $\begin{array}{l}\text { Regional nodal involvement } \\
\text { Yes/No }\end{array}$ & $60 / 93$ & $39.2 / 60.8$ \\
\hline $\begin{array}{l}\text { Local tumour invasion } \\
\text { Yes/no }\end{array}$ & $44 / 109$ & $28.8 / 71.2$ \\
\hline Type of treatment & 25 & 32.1 \\
\hline Chemotherapy only & 79 & 51.6 \\
\hline Radiotherapy only & 49.3 \\
\hline Chemo-radiotherapy & 19.4 \\
\hline
\end{tabular}




\section{Treatment}

Radiotherapy only was the treatment used in 79 patients (51.6\%), chemotherapy only in 25 (16.3\%), chemotherapy followed by radiotherapy in $33(21.6 \%)$, radiotherapy followed by chemotherapy in $14(9.2 \%)$, and concurrent chemoradiotherapy in $2(1.3 \%)($ Table 1$)$. The early stages were treated with radiotherapy only in 77 cases $(57.5 \%)$ (nasal $=73$ ), chemotherapy only in $11(8.2 \%)($ nasal $=9)$, chemotherapy followed by radiotherapy in 32 cases $(23.9 \%$ ) (nasal $=22$ ), radiotherapy followed by chemotherapy in $12(8.9 \%)($ nasal $=11)$, concurrent chemoradiotherapy in $2(1.5 \%)$ (nasal $=2$ ). None of these patients underwent haematopoietic stem cell transplantation. The advanced stages were treated with radiotherapy only in two cases $(10.5 \%)$ (nasal $=1)$, chemotherapy only in $14(73.7 \%)($ nasal $=6)$, and chemotherapy followed by radiotherapy in one case $(5.3 \%)$ (non-nasal = 1), radiotherapy followed by chemotherapy in two cases $(10.5 \%)($ nasal $=2)$.

Chemotherapy regimen used was cyclophosphamide, doxorubicin, vincristine, and prednisone $(\mathrm{CHOP})$ in seven patients $($ early stages $\mathrm{n}=2$ , advanced stages $n=5)$ and CHOEP-14 (CHOP + etoposide) in 18 (early stages $n=9$ ) patients. No one patient received SMILE regimen (dexamethasone, methotrexate, ifosfamide, l-asparaginase, and etoposide) as it was included as a salvage treatment just at the end of 2013. The chemotherapy regimens used either as monotherapy, prior, concurrent, or followed by radiotherapy were $\mathrm{CHOP}$ in 33 (44.5\%), $\mathrm{CHOEP}-14$ in $40(54.1 \%)$, and other regimen in one case $(1.4 \%)$, totalling 74 patients with this type of treatment.

Twenty-five patients received chemotherapy only (early stages $n=11$ ), ranging the number of cycles of chemotherapy between 1 and 8 with a median of 2.5 cycles. Among the patients in early stages receiving chemotherapy followed by radiotherapy with number of cycles ranging between 1 and 8 , we find $69.6 \%$ (23 out of 33 ) received six cycles. It was also noted that only one patient with advanced disease received this modality of treatment.

\section{Treatment response}

The early stages had response rates as follows: CR $n=92(68.7 \%)($ stage I = 68, stage II = 24) PR $n=16(11.9 \%)($ stage I = 10, Stage II = 6), SD $n=3(2.2 \%)$ (stage I = 2, stage II =1), PD $n=23(17.2 \%)($ stage I = 11, stage II = 12). The advanced diseases had response rates as follows: $\mathrm{CR} n=7$ (36.8\%) (stagellI = 1, stage IV = 6), PR $n=5(26.4 \%)($ stage IV = 5), SD $n=0$, PD $n=7(36.8 \%)($ stage III = 1 , stage IV = 6).

\section{Progression-free survival}

With a median follow-up time of 18 months, the median PFS time was 20 months (95\% Cl 0-41), and the five year PFS rate was $42.6 \%$. The variables that showed statistical significance towards a worse outcome in the univariate analysis were male sex, non-nasal primary site, advanced clinical stages, presence of B symptoms, poor performance status (PS), and nodal involvement. The median PFS for the nasal primary was 79 months $(95 \% \mathrm{Cl} 14-143)$ and the five year PFS was $50.9 \%$ as shown in Figure 1 and Table 2 . The six variables with statistical significance were studied by multivariate analysis, showing that the only independent poor prognostic factor was primary nonnasal site $(\mathrm{HR}=2.40,95 \% \mathrm{Cl}=1.43-4.02, \mathrm{P}=0.01)($ Table 2$)$.

\section{Overall survival}

Seventy-five patients (49\%) had died by the time of the analysis. With a median follow-up of 48 months (1-143 months). The median OS time was 49 months $(95 \% \mathrm{Cl} 0-98)$ and the five year OS rate was $48.9 \%$ (Figure 2). The factors that showed statistical significance towards a worse outcome in the univariate analysis were non-nasal primary site, advanced clinical stage, presence of B symptoms, increased LDH, nodal involvement and local tumour invasion. For nasal primary the median OS time was not reached and the five year OS rate was $55.8 \%$ as shown in Table 3 and Figure 3. The multivariate analysis showed that the only poor prognostic factor was primary non-nasal site $(\mathrm{HR}=2.57,95 \%$ $\mathrm{Cl}=1.37-4.83, \mathrm{P}=0.03$ ) (Table 3$)$.

We performed a sub-analysis for early disease and we found the median OS for nasal primary $(117,87.3 \%)$ was not reached and that for non-nasal primary $(17,12.6 \%)$ was 17 months, $p=0.003$. In the multivariate analysis we identified three factors for poor prognosis, nonnasal site $(H R=3.1,95 \% \mathrm{Cl} 1.50-6.37 \mathrm{p}=0.002)$, presence of $\mathrm{B}$ symptoms $(\mathrm{HR}=1.86,95 \% \mathrm{Cl} 1.037-3.34, \mathrm{p} 0.037)$, and $\mathrm{DHL}>\mathrm{normal}$ $(\mathrm{HR}=1.84,95 \% \mathrm{Cl} 1.04-3.27, \mathrm{p}=0.035)$. 


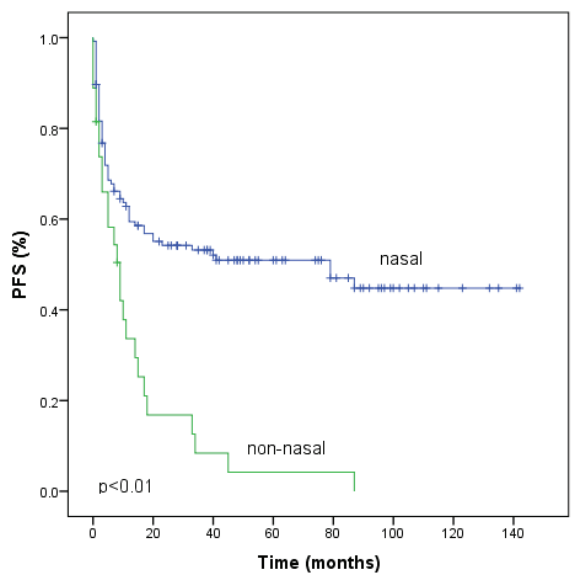

Time (months)

Figure 1. Progression-free survival (PFS) according to primary site of natural killer/T-cell lymphoma. Primary nasal $(n=126)$ and $n o n-n a s a l(n=27)$.

Table 2. PFS according to patients features and univariate/multivariate analysis of prognostic factors.

\begin{tabular}{|c|c|c|c|c|c|c|}
\hline \multirow{2}{*}{ Characteristics } & \multirow{2}{*}{$\mathbf{N}$} & \multirow{2}{*}{$\begin{array}{l}\text { Median, } \\
\text { months }\end{array}$} & \multirow{2}{*}{$\begin{array}{c}\text { Five year } \\
\text { survival } \\
\text { rate, } \%\end{array}$} & \multirow{2}{*}{$\begin{array}{c}\begin{array}{c}\text { Univariate } \\
\text { analysis }\end{array} \\
\mathbf{p} \\
\end{array}$} & \multicolumn{2}{|c|}{ Multivariate analysis } \\
\hline & & & & & HR (95\% Cl) & p \\
\hline \multicolumn{7}{|l|}{ Age, years } \\
\hline$\leq 60$ & 131 & 17 & 41.9 & & & \\
\hline$>60$ & 22 & 40 & 45.5 & 0.376 & & \\
\hline Sex (male/Female) & $98 / 55$ & $12 / 79$ & $37.5 / 51.3$ & 0.033 & & \\
\hline \multicolumn{7}{|l|}{ Primary site } \\
\hline Nasal & 126 & 79 & 50.9 & & $2.40(1.43-4.02)$ & 0.01 \\
\hline Non-nasal & 27 & 9 & 4.2 & $<0.001$ & & \\
\hline \multicolumn{7}{|l|}{ Stage } \\
\hline Early (I-II) & 134 & 33 & 46.7 & & & \\
\hline Advanced (III-IV) & 19 & 7 & 14 & 0.002 & & \\
\hline \multicolumn{7}{|l|}{ B symptoms } \\
\hline Yes & 55 & 7 & 33.2 & & & \\
\hline No & 98 & 40 & 50.6 & 0.016 & & \\
\hline \multicolumn{7}{|l|}{ PS } \\
\hline 1 & 138 & 33 & 44.5 & & & \\
\hline 2 & 15 & 4 & 26.7 & 0.028 & & \\
\hline \multicolumn{7}{|l|}{ LDH } \\
\hline >normal & 58 & 11 & 38.1 & & & \\
\hline snormal & 83 & 45 & 50.0 & 0.060 & & \\
\hline \multicolumn{7}{|c|}{ Regional nodal involvement } \\
\hline Yes & 60 & 7 & 27.9 & & & \\
\hline No & 93 & 79 & 51.9 & 0.005 & & \\
\hline $\begin{array}{l}\text { Local tumour invasion } \\
\text { Yes/No }\end{array}$ & $44 / 109$ & $12 / 40$ & $31.7 / 46.9$ & 0.083 & & \\
\hline
\end{tabular}

$\mathrm{NR}=$ Not reached, $\mathrm{PFS}=$ progression-free survival 


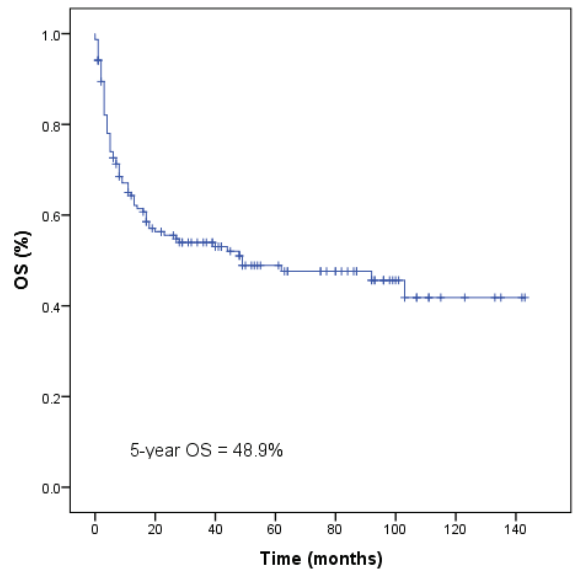

Figure 2. Survival of 153 natural killer/T-cell lymphoma patients. OS, overall survival.

Table 3. Overall survival, according to patient features and univariate/multivariate analysis of prognostic factors.

\begin{tabular}{|c|c|c|c|c|c|c|}
\hline \multirow{2}{*}{ Characteristics } & \multirow{2}{*}{$\mathbf{N}$} & \multirow{2}{*}{$\begin{array}{l}\text { Median, } \\
\text { months }\end{array}$} & \multirow{2}{*}{$\begin{array}{c}\text { Five year } \\
\text { survival } \\
\text { rate, } \%\end{array}$} & \multirow{2}{*}{$\begin{array}{c}\text { Univariate } \\
\text { analysis }\end{array}$} & \multicolumn{2}{|c|}{ Multivariate analysis } \\
\hline & & & & & HR $(95 \% \mathrm{Cl})$ & p \\
\hline$\leq 60$ & 131 & 49 & 49 & & & \\
\hline$>60$ & 22 & 49 & 48.3 & 0.572 & & \\
\hline Sex (male/female) & $98 / 55$ & $40 / \mathrm{NR}^{(*)}$ & $45.8 / 54.1$ & 0.106 & & \\
\hline \multicolumn{7}{|l|}{ Primary site } \\
\hline Nasal & 126 & $\mathrm{NR}^{(*)}$ & 55.8 & & & \\
\hline Non-nasal & 27 & 11 & 16.0 & $<0.001$ & $2.57(1.37-4.83)$ & 0.03 \\
\hline \multicolumn{7}{|l|}{ Stage } \\
\hline Early (I-II) & 134 & 92 & 52.8 & & & \\
\hline Advance (III-IV) & 19 & 8 & 21.1 & 0.005 & & \\
\hline B Symptoms (yes/no) & $55 / 98$ & $13 / 103$ & $37.6 / 55.2$ & 0.014 & & \\
\hline \multicolumn{7}{|l|}{ PS } \\
\hline 1 & 138 & 62 & 50.1 & & & \\
\hline 2 & 15 & 8 & 40.0 & 0.160 & & \\
\hline \multicolumn{7}{|l|}{$\mathrm{LDH}$} \\
\hline >normal & 58 & 17 & 43.8 & & & \\
\hline$\leq$ normal & 83 & $\mathrm{NR}^{(*)}$ & 57.9 & 0.018 & & \\
\hline \multicolumn{7}{|l|}{$\begin{array}{l}\text { Regional nodal involve- } \\
\text { ment }\end{array}$} \\
\hline Yes & 60 & 11 & 35.4 & & & \\
\hline No & 93 & $\mathrm{NR}^{(*)}$ & 57.5 & 0.002 & & \\
\hline \multicolumn{7}{|l|}{ Local tumour invasion } \\
\hline Yes & 44 & 13 & 39.3 & & & \\
\hline No & 109 & 103 & 52.5 & 0.040 & & \\
\hline
\end{tabular}

$\left.{ }^{*}\right)$ : Not reached 


\section{Discussion}

We present here 153 NKTCL patients who fulfilled our selection criteria diagnosed over a period of ten years. To the best of our knowledge it is the largest Latin American study in NKTCL patients [4-8] and the second largest in the whole American continent [9-12]. The number of patients were similar to some seen in multicentre studies [2, 13, 15, 20-22, 32-36]. The present study shows that the clinical characteristics of nasal NKTCL in Peru are similar to those described in other Latin American as well as Asian and Western countries [2, 3, 6, 8, 9, $29,30]$. The treatment used in our population was according to the clinical staging, with radiotherapy only or concurrent with chemotherapy for early stages, and chemotherapy only for advanced disease, as is described in the international literature [31]. L-asparaginase-based regimen (SMILE treatment) was not part of the treatment, as this was incorporated in our institution just in 2013 [37].

In this series, the PFS was 20 months which is similar to reported by Huang et al at 18 months [21]. However, the five year PFS was 29.8\% which is lower than our study where the five year PFS was $42.6 \%$. This discrepancy might be because of a lower proportion of patients with presence of B symptoms in our study (36\% versus $54 \%$, respectively) and also could have influenced the higher percentage of patients with early stages in our study (83\% versus $79.5 \%$, respectively). In contrast, Lee et al [16] showed a five year relapse-free survival (RFS) of $60 \%$. This result is different because this was calculated on patients who had achieved complete remission.

In our study, we show that patients with NKTCL have poor survival, with a median OS of 49 months. In other studies, the median OS has ranged between 30 and 50 months [2, 16, 21, 34]. However, when we consider the survival for non-nasal NKTCL this was nine months, different from data reported by Au et al [3] where extranasal cases had a median OS of four months. This was probably because $19 \%$ of those patients did not receive treatment because of advanced disease unlike our study where all patients received treatment.

Regarding the cumulative probability of survival at five years, our study shows a $49 \%$ OS rate, whereas in other studies it ranged between $39 \%$ and $50 \%$. [13, 16, 21, 34, 37, 38]. When evaluating the non-nasal primary this was $16 \%$ which is comparable to the study of Au et al [3]. Only a non-nasal primary site was an independent adverse predictor in the multivariate analysis which we find is also the same variable identified in other studies [3,12, 16, 32]. The primary site of this type of lymphoma had been evaluated previously but with the term upper aerodigestive tract NKTCL. This included lymphomas confined to nasal cavity, nasopharynx, larynx, pharynx, and oral cavity [16]. In our study nasal type refers only to nasal cavity.

In our study, we found that the primary site is more important than clinical stage as independent prognostic risk factor, and this finding was reported by Au et al's study. Even non-nasal primary with apparently localised disease had poor prognosis [3]. The biological distinction between these two subgroups remains unknown, hence necessitating future studies with genetic and epigenetic profiling.

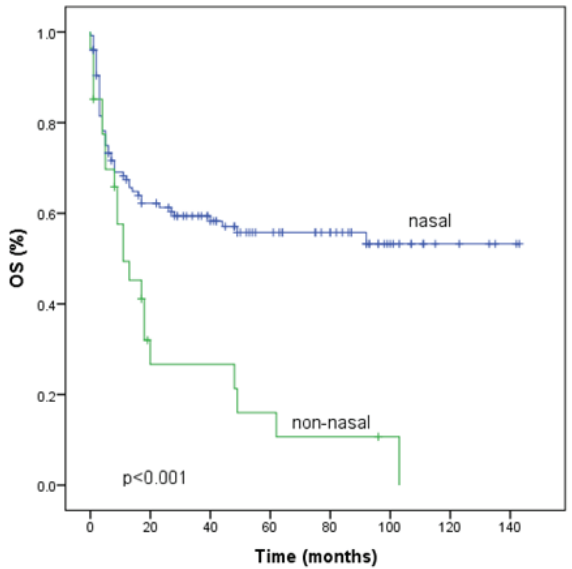

Figure 3. Survival according to primary site of natural killer/T-cell lymphoma. OS, overall survival. 
Other prognostic factors have been evaluated in NKTCL patients such as Ki-67 expression, EBV viral load, lymphocyte and monocyte counts [19, 21, 25, 33]. In the last years c-Myc expression, beta-2 microglobulin, CD30-CD38 expression, the albumin to globulin ratio [38-44], CD56 expression, higher levels of HLA-DR negative, CD33, CD11b myeloid-derived suppressor cells (MDSCs), CD14 monocytic MDSCs, independent adverse prognostic scores have also been used for evaluation [45]. However, in our study we could not evaluate these factors either because of incomplete baseline data or because of lack of tests for these factors in our centre.

\section{Conclusion}

In conclusion, in Peru the OS for NK/T-cell lymphoma is similar to other Latin American as well as Asian countries. The results suggest that non-nasal NKTCL is the only poor prognostic factor of OS and PFS which we find is even more important than the clinical staging itself. This poor prognostic factor is seen in early stages as well. It is important to conduct multicentre prospective studies including the most important clinical, laboratorial, pathological, and viral prognostic factors in order to make an accurate prognostic index.

\section{Conflict of interest}

The authors declare no competing financial interests.

\section{References}

1. Swerdlow SH et al (2008) WHO Classification of tumours of haematopoietic and lymphoid tissues. International Agency for Research on Cancer (IARC) 4th Edition, Lyon. 285-88

2. Xu PP et al (2012) Prognostic factors of Chinese patients with T/NK-cell lymphoma: a single institution study of $\mathbf{1 7 0}$ patients Med Oncol 29(3) 2176-82 DOI: 10.1007/s12032-011-0011-0

3. Au WY et al (2009) Clinical differences between nasal and extranasal natural killer/T-cell lymphoma: a study of $136 \mathrm{cases}$ from the International Peripheral T-Cell Lymphoma Project. Blood 113(17) 3931-7 DOI: 10.1182/blood-2008-10-185256

4. Arber DA et al (1993) Nasal lymphomas in Peru: High incidence of T-cell immunophenotype and Epstein-Barr virus infection Am J Surg Pathol 17(4) 392-9 DOI: $\underline{10.1097 / 00000478-199304000-00010}$ PMID: $\underline{8388175}$

5. Quintanilla-Martinez L et al (1999) Histological and immunophenotypic profile of nasal NK/T cell lymphomas from Peru: high prevalence of p53 overexpression Hum Pathol 30(7) 849-55 DOI: 10.1016/S0046-8177(99)90147-8 PMID: 10414505

6. Cabrera ME et al (2007) Nasal natural killer/T-cell lymphoma and its association with type "i"/Xhol loss strain Epstein-Barr virus in Chile J Clin Pathol 60(6) 656-60 DOI: 10.1136/jcp.2005.034199

7. Barrionuevo $\mathrm{C}$ et al (2007) Extranodal NK/T-cell lymphoma, nasal type: study of clinicopathologic and prognosis factors in a series of 78 cases from Peru Appl Immunohistochem Mol Morphol 15(1) 38-44 DOI: 10.1097/01.pai.0000205062.27174.56 PMID: 17536305

8. Gualco $\mathrm{G}$ et al (2011) Clinicopathologic and molecular features of 122 Brazilian cases of nodal and extranodal NK/T-cell lymphoma, nasal type, with EBV subtyping analysis Am J Surg Pathol 35(8) 1195-203 DOI: 10.1097/PAS.0b013e31821ec4b5 PMID: $\underline{21716086}$

9. Van de Rijn M et al (1997) Extranodal head and neck lymphomas in Guatemala: high frequency of Epstein-Barr Virus-associated sinonasal lymphomas Hum Pathol 28(7) 834-9 DOI: 10.1016/S0046-8177(97)90158-1 PMID: $\underline{9224753}$

10. Khan $L$ et al (2015) A single institution experience of extranodal natural killer/T cell lymphoma of nasal type Leuk Lymphoma 56(1) 80-4 DOI: $\underline{10.3109 / 10428194.2014 .909039}$ 
11. Avilés A (2015) Nasal NK/T-cell lymphoma. A comparative analysis of a Mexican population with the other populations of Latin-America Mediterr J Hematol Infect Dis 7(1) e2015052 DOI: 10.4084/mjhid.2015.052 PMID: 26401241 PMCID: 4560257

12. Li S et al (2013) Extranodal NK/T-cell lymphoma, nasal type: a report of 73 Cases at MD Anderson Cancer CenterAm J Surg Pathol 37(1) 14-23 DOI: 10.1097/PAS.0b013e31826731b5

13. Vose J, Armitage J and Weisenburger D (2008) International T-Cell Lymphoma Project. International peripheral T-cell and natural killer/T-cell lymphoma study: pathology findings and clinical outcomes J Clin Oncol 26(25) 4124-30 DOI: 10.1200/

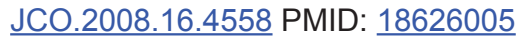

14. Ahn HK et al (2012) Extranodal natural killer/T-cell lymphoma from skin or soft tissue: suggestion of treatment from multinational retrospective analysis Ann Oncol 23(10) 2703-7 DOI: 10.1093/annonc/mds096 PMID: 22547542

15. Li YX et al (2008) Clinical features and treatment outcome of nasal-type NK/T-cell lymphoma of Waldeyer ring Blood 112(8) 3057-64 DOI: 10.1182/blood-2008-05-160176 PMID: 18676879

16. Lee $\mathrm{J}$ et al (2006) Extranodal natural killer T-cell lymphoma, nasal-type: a prognostic model from a retrospective multicenter study J Clin Oncol 24(4) 612-8 DOI: 10.1200/JCO.2005.04.1384

17. Kohrt H, Lee M and Advani R (2010) Risk stratification in extranodal natural killer/T-cell lymphoma Expert Rev Anticancer Ther 10(9)1395-405 DOI: 10.1586/era.10.130 PMID: 20836675

18. Li YJ et al (2013) The Glasgow Prognostic Score (GPS) as a novel and significant predictor of extranodal natural killer/T-cell lymphoma, nasal type Am. J Hematol 88(5) 394-9 DOI: 10.1002/ajh.23422 PMID: 23423859

19. Jiang L1 et al (2014) Prognostic significance of Ki-67 antigen expression in extranodal natural killer/T-cell lymphoma, nasal type Med Oncol 31(10) 218 DOI: 10.1007/s12032-014-0218-y PMID: 25204411

20. Huang JJ et al (2012) A novel prognostic model for extranodal natural killer/T-cell lymphoma Med Oncol 29(3):2183-90 DOI: 10.1007/s12032-011-0030-x

21. Huang $\mathrm{JJ}$ et al (2011)Absolute lymphocyte count is a novel prognostic indicator in extranodal natural killer/T-cell lymphoma, nasal type Ann Oncol 22(1) 149-55 DOI: 10.1093/annonc/mdq314

22. Chen $\mathrm{KL}$ et al (2015) The prognostic nutritional index predicts survival for patients with extranodal natural killer/T cell lymphoma, nasal type 94(8) 1389-400 PMID: 25869028

23. Kim TM et al (2005) Local tumor invasiveness is more predictive of survival than International Prognostic Index in stage IE/IIE extranodal NK/T-cell lymphoma, nasal type Blood 106(12) 3785-90 DOI: 10.1182/blood-2005-05-2056 PMID: 16109779

24. Chim CS et al (2004) Primary nasal natural killer cell lymphoma: long-term treatment outcome and relationship with the International Prognostic Index Blood 103(1) 216-21 DOI: 10.1182/blood-2003-05-1401

25. Hsieh PP et al (2007) EBV Viral Load in tumor tissue is an important prognostic indicator for nasal NK/T-cell lymphoma Am J Clin Pathol 128(4) 579-84 DOI: 10.1309/MN4Y8HLQWKD9NB5E PMID: 17875508

26. Lister TA et al (1989) Report of a committee convened to discuss the evaluation and staging of patients with Hodgkin's disease: Costwolds meeting J Clin Oncol 7(11) 1630-6 PMID: 2809679

27. Oken MM et al (1982) Toxicity and response criteria of the Eastern Cooperative Oncology Group Am J Clin Oncol 5(6) 649-55 DOI: 10.1097/00000421-198212000-00014 PMID: $\underline{7165009}$

28. Cheson BD et al (1999) Report of an international workshop to standardize response criteria for non-Hodgkin's lymphomas. NCI Sponsored International Working Group J Clin Oncol 17(4) 1244 PMID: 10561185

29. Pagano L et al (2006) NK/T-cell lymphomas 'nasal type': an Italian multicentric retrospective survey Ann Oncol 17(5) 794-800 DOI: $\underline{10.1093 / a n n o n c / m d l 015}$ PMID: 16497823 
30. McKelvie PA, Thompson PA and Tam CS (2012) Peripheral T cell and natural killer (NK) T cell lymphomas: a clinicopathological study from a single Australian centre Histopathology 61(2) 212-23. DOI: 10.1111/j.1365-2559.2012.04238.x PMID: 22716228

31. Chaudhary Rk, Bhatt VR and Vose JM (2015) Management of extranodal natural killer/T-cell lymphoma, nasal type Clin Lymphoma, Myeloma Leuk 15(5) 245-52 DOI: 10.1016/j.clml.2014.12.014

32. Suzuki R et al (2010) Prognostic factors for mature natural killer (NK) cell neoplasms: aggressive NK cell leukemia and extranodal NK cell lymphoma, nasal type Ann Oncol 21(5) 1032-40 DOI: 10.1093/annonc/mdp418

33. Huang JJ et al (2013) Prognostic significance of peripheral monocyte count in patients with extranodal natural killer/T-cell lymphoma BMC Cancer 13222 DOI: 10.1186/1471-2407-13-222 PMID: 23638998 PMCID: $\underline{3653743}$

34. Cai $Q$ et al (2013) Fasting blood glucose is a novel prognostic indicator for extranodal natural killer/T-cell lymphoma, nasal type Br J Cancer 108(2) 380-6 DOI: 10.1038/bjc.2012.566 PMID: 23299534 PMCID: 3566812

35. Cai $Q$ et al (2014) New prognostic model for extranodal natural killer/T cell lymphoma, nasal type Ann Hematol 93(9) 1541-9f Canc DOI: 10.1007/s00277-014-2089-x PMID: 24782120

36. Watanabe $T$ et al (2010) Pretreatment total serum protein is a significant prognostic factor for the outcome of patients with peripheral T/natural killer-cell lymphomas Leuk Lymphoma 51(5) 813-21 DOI: 10.3109/10428191003721359 PMID: 20367565

37. Kwong YL et al (2012) SMILE for natural killer/T-cell lymphoma: analysis of safety and efficacy from the Asia Lymphoma Study Group Blood 120(15) 2973-80 DOI: 10.1182/blood-2012-05-431460 PMID: 22919026

38. Huang X et al (2014) Both c-Myc and Ki-67 expression are predictive markers in patients with Extranodal NK/T-cell lymphoma, nasal type: a retrospective study in China Pathol Res Pract 210(6) 351-6 DOI: 10.1016/j.prp.2014.02.004 PMID: 24642368

39. Yoo $\mathrm{C}$ et al (2014) Prognostic impact of beta-2 microglobulin in patients with extranodal natural killer/T cell lymphoma Ann Hematol 93(6)995-1000 DOI: 10.1007/s00277-014-2015-2 PMID: 24441948

40. Kim WY et al (2015) Prognostic implications of CD30 expression in extranodal natural killer/T-cell lymphoma according to treatment modalities Leuk Lymphoma 56(6) 1778-86 DOI: 10.3109/10428194.2014.974048

41. Wang L et al (2015) CD38 expression predicts poor prognosis and might be a potential therapy target in extranodal NK/T cell lymphoma, nasal type Ann Hematol 94(8) 1381-8 DOI: 10.1007/s00277-015-2359-2 PMID: 25865943

42. $\mathrm{Bi} X \mathrm{X}$ et al (2016) The pretreatment albumin to globulin ratio predicts survival in patients with natural killer/T-cell lymphoma PeerJ 4:e1742. DOI: 10.7717/peerj.1742 PMID: 26966671 PMCID: $\underline{4782740}$

43. Kim SJ et al (2016) A prognostic index for natural killer cell lymphoma after non-anthracycline-based treatment: a multicentre, retrospective analysis Lancet Oncol 17(3) 389-400 DOI: 10.1016/S1470-2045(15)00533-1 PMID: 26873565

44. Liang $\mathrm{R}$ et al (2016) Natural killer/T cell lymphoma, nasal type: a retrospective clinical analysis in North-Western China Oncol Res Treat 39(1-2) 45-52 DOI: 10.1159/000442763 PMID: 26891121

45. Zhang $\mathrm{H}$ et al (2015) Myeloid-derived suppressor cells inhibit $\mathrm{T}$ cell proliferation in human extranodal NK/T cell lymphoma: a novel prognostic indicator Cancer Immunol Immunother 64(12) 1587-99 DOI: 10.1007/s00262-015-1765-6 PMID: 26497849 PMCID: $\underline{4643115}$ 